expert advice has been provided to Member States on questions relating to environmental monitoring. Plans are also being made for a bio-assay service for radiochemical analysis of biological samples from atomic energy installations in the less-developed countries.

In the Medical and Health Physics Section, a whole-body counter is expected to be in operation from next Spring for measurements on radiation workers, at the request of Member States. The facility will also be used for the study of certain problems of immediate interest to the Agency's own work in the health physics field. For example, a study of radiation doses received by patients who have been given thorotrast for diagnostic purposes is expected to yield useful data on the late effects of small amounts of incorporated radioactivity; such data will be supplementary to those obtained by examining radium-dial painters.
The Laboratory has a well-equipped Electronics Section, which is mainly a servicing unit. A Chemistry Section is expected to be in full operation next Spring; a major part of its work will be concerned with analytical chemistry, particularly trace element analysis.

Another section of the Laboratory will deal specially with the applications of tritium in hydrology. The Agency has already started furnishing tritium laboratories in various countries with water standards in connexion with its programme for a world-wide survey of hydrogen and oxygen isotopes.

The Laboratory has its own workshop and library.

Twelve scientists from eight countries are at present employed in the Laboratory. In addition, there are 15 staff members in the general service category. The approved complement for 1962 provides for 17 professional and 28 general service staff members.

\title{
RADIOBIOLOGICAL RESEARCH UNIT, HARWELL
}

$\mathrm{T}$ HE Medical Research Council established its Radiobiological Research Unit at the Atomic Energy Research Establishment, Harwell, in 1947. As the name implies, its activities are devoted to the investigation of the fundamental action of ionizing radiation in living systems, and thereby to providing the solution of potential or actual problems that arise from developments in the use of nuclear energy.

By 1954 the Unit (director, Dr. J. F. Loutit) had expanded to approximately its present size, forming six interdependent sections: Experimental Pathology (Dr. R. H. Mole, now deputy director), Physiology (Dr. O. A. Trowell), Biophysics (Dr. G. J. Neary), Biochemistry (Mr. J. St. L. Philpot), Radiochemistry (Dr. G. E. Harrison) and Cytogeneties (Dr. C. E. Ford). It was then joined by a Genetics Section from Edinburgh, headed then by Dr. T. C. Carter and now by Dr. A. L. Searle.

Since it occupied its permanent quarters in 1953 , the Unit has been in the unrestricted area of the Atomic Energy Research Establishment, but on November 28, 1961, it held for the first time an open day for the Press, each section providing one or two demonstrations as an illustration of its present work.

Dr. D. Lucas (Physiology) demonstrated shortterm culture in vitro, which maintains small organs or fragments of tissue alive for several days in a chemically defined medium. This provides a means for scoring effects of radiation directly and uninfluenced by interactions in vivo. Radiosensitivity of the cells of rat lymph nodes is markedly affected by changes in oxygen tension; that of visual cells of guinea pig retina less so. This system has been used for comparing the effects of radiation and chemical toxins, and could be applied for the testing of radioprotective chemical agents.

Dr. A. L. Batchelor and Mr. F. Williamson (Biophysics) illustrated that in collaboration with the Atomic Energy Research Establishment the lowpower reactor, Gleep, had been utilized for the past ten years as a source of low-intensity fast neutrons for the chronic irradiation of populations of small animals resident therein. By comparison with cobalt-60 $\gamma$-rays, the relative biological effectiveness of these fast neutrons from uranium fission for several biological parameters was determined to be around 10. Bepo, the 6-MW. graphite-moderated natural uranium reactor, is now being adapted as a source of high-intensity fast neutrons capable of providing dose-rates of some hundreds of rads per hour in a pit of substantial size. The dosimetry of fast neutrons is effected by intercomparison of three ionization chambers, each responding primarily to fast neutrons, thermal neutrons and $\gamma$-rays: the absolute accuracy for fast neutrons is estimated as \pm 18 per cent.

Dr. H. J. Evans (also of Biophysics) reviewed the effects of radiation on the chromosomes of simple cell systems. Chromatid and chromosome breakage were shown in cells of root meristems of Vicia faba. On irradiation of Tradescantia pollen with $\gamma$-rays in atmospheres of 0-21 per cent oxygen, a remarkable increase in chromosome aberrations at low oxygen tensions was evident. With fast neutron irradiation, on the other hand, an oxygen effoct was minimal.

Dr. A. L. Searle and Dr. J. Godfrey (Genetics), having noted that most of the work on mouse radiation genetics has been concerned with mutation at specific loci, have begun to consider polygenic systems and the biological fitness of murine populations derived from an irradiated parent. Dr. Searle showed that the descendants of two sublines of $C 3 H$ exposed for 10 generations to $1 \mathrm{r}$. of $\gamma$-radiation each night showed paradoxically less divergence in certain motrical and other characters than two unirradiated sublines. On the other hand, Dr. Godfrey's offspring of irradiated mice had lower indices of fitness than comparable offspring of normal mice, the two populations being identifiable in the same common 'tenement' by a 'marker-gene'.

Dr. Jean Stanier (Biochemistry) reviewed several aspects of the work of this Section, much of which is concerned with metabolism of the cell nucleus. An airborne centrifuge has been developed for the separation of the contents of ruptured liver colls. Media 
for the maintenance in vitro of the separated nuclei are under test. Enzymes, particularly deoxyribonuclease and ribonuclease, which preclude such maintenance, have to be inhibited: $\alpha$-angelica lactone has RNase inhibitory properties. Furthermore, conditions necessary for synthesis of deoxyribonucleic acid are under investigation. Of immediate relevance to problems of irradiation, the production of peroxides in irradiated mice has been measured and new radioprotective chemical agents are being sought: polyphosphates and other ring compounds have been examined.

Mr. T. E. F. Carr (Radiochemistry) gave results for three human subjects on a month's diet, basically of bread and milk, in which the milk strontium was marked with strontium -85 and the cereal strontium with strontium-90. The experiment indicated that there was little difference between the two sources in the availability of strontium for absorption by the intestine.

Dr. E. V. Hulse (Experimental Pathology) demonstrated an apparatus containing a hollow cylinder of radioactive foil emitting $\beta$-rays by means of which suporficial irradiation of mice has been effected. It has been found that 3,000 rads produce one malignant neoplasm per $50 \mathrm{~cm} .{ }^{2}$ of skin. Most of the malignant tumours so far scored have been sarcomas, but a few typical squamous-cell carcinomas also occur.

Dr. D. W. H. Barnes (also of Experimental Pathology) reviewed the problem of 'secondary disease' of lethally-irradiated mice treated with myeloid tissue. Such 'secondary disease' in $C B A$ mice was not confined to those treated with antigenically foreign tissue. When it occurred in mice given isogeneic tissue it was markedly reduced if suspensions of mature lymphatic tissue were added to the myeloid cells.

Dr. C. M. Clarke (Cytogenetics) surveyed some work on the chromosomes of mammals permitted by the colchicine-hypotonic-medium squash preparation. In irradiated mice with 40 acrocentric chromosomes, though not providing ideal material, the competition between, and spread of, clones could be scored in reticular tissues. Chinese hamsters $(2 n=22)$ pro. vided much better material, and man $(2 n=46)$ is now being extensively studied. The identification of clones in cases of acute leukæmia was reported.

\section{BRITISH COMMONWEALTH MEDICAL RESEARCH}

$I^{\mathrm{N}}$ $\mathrm{N}$ written answers to questions in the House of Commons on December 18, the Secretary for Technical Co-operation, Mr. D. Vosper, said that expenditure from Colonial Development and Welfare Funds in the year ended March 31, 1961, was $£ 76,275$ and the Medical Research Council expended a further $£ 2,000$.

Expenditure on onchocerciasis research was estimated at about $£ 3,800$ between the same sources. The main centre of such research overseas was the Helminthiasis Research Unit of the West African Council for Medical Research, which investigated all aspects of this disease, including research into the breeding grounds, habits and possibilities of extermination of the vector, Simulium damnosum. Four British entomologists under a British director were employed at the Unit, which was now financed entirely by the independent Governments of Nigeria, Ghana and Sierra Leone and the Government of the Gambia, apart from a contribution from Colonial Development and Welfare Funds to the last named. In Uganda, research into the disease and its vector was conducted by two British entomologists employed by the Uganda Government, and in Kenya the work of British entomologists had eradicated the disease. In Britain important research was conducted at the Liverpool School of Tropical Medicine and at the British Museum (Natural History).

When the subject was raised in an adjournment debate on the following day by Mr. Leslie Hale, who complained that copies of the Rodger Report into blindness in West Africa and other recent reports on the causes and prevention of these diseases had not been placed in the Library of the House of Commons, Mr. Vosper, after a tribute to the work of the Royal Commonwealth Society for the Blind, said that research into trypanosomiasis in Africa had been on a co-operative basis and the British share had taken three forms. We had been associated with the establishment and maintenance of the East African
Inter-Territorial Research Station in Uganda. We had assisted similarly with the corresponding station in Northern Nigeria, and at the instigation of the United Kingdom Committee work was now also being carried out at various centres in the United Kingdom. Mr. Vosper instanced research projects at the London School of Hygiene and Tropical Medicine, at the University of Liverpool and Liverpool School of Tropical Medicine, at the Lister Institute of Preventive Medicine, and a special laboratory being built at the University of Bristol should be ready next summer.

Expenditure from Colonial Development and Welfare Funds during the past quinquennium was just short of $£ 500,000$, apart from the work carried on by the Medical Research Council and Colonial Governments. While this work was a record of success and the limitations were now the provision of medical services and the willingness of the population to take advantage of them, the position with onchocerciasis was less satisfactory. In Kenya it had been practically eradicated, in Tanganyika curbed, and in Uganda greatly reduced by the use of DDT. Research was continuing in Uganda, which had been visited early this year by two research workers from Britain, and there had been concentrated research in West Africa for fifteen years, mainly at the $\mathrm{Hel}$ minthiasis Research Unit of the West African Council for Medical Research at Kumba in the Cameroon Republic, with an out-station at Bolge Tanga in Ghana. The Unit continued to investigate most aspects of the problem, and the Royal Commonwealth Society for the Blind had recently made an independent survey of the problem. While finance was now the initial responsibility of the independent Governments, Mr. Vosper did not think that more finance would necessarily provide a solution, though he agreed that technical co-operation might find a way to help. 